\title{
Maneuverability of an Inverted Pendulum Vehicle According to the Handle Operation Methods
}

\author{
Chihiro NAKAGAWA, Takuya CHIKAYAMA, Akikazu OKAMOTO, Atsuhiko SHINTANI and Tomohiro ITO \\ Graduate School of Engineering, Osaka Prefecture University \\ 1-1, Gakuen, Naka, Sakai, Osaka, 599-8531, Japan
}

\begin{abstract}
This study investigated what handle operation and turning gain is comfortable for people using an inverted pendulum vehicle that is changeable the handle operation. Experimental conditions were three conditions. First is a slalom course with two cones placed at an interval of $1.8 \mathrm{~m}$. Second is a slalom course with five cones placed at an interval of $1.4 \mathrm{~m}$. Third is a slalom course with six cones placed at $1.8 \mathrm{~m}, 1.4 \mathrm{~m}$, $1.8 \mathrm{~m}, 1.4 \mathrm{~m}, 1.8 \mathrm{~m}$, and $1.8 \mathrm{~m}$ interval. The first condition considered the difference of handle operation between subjects who were used to ride and not used to ride. The second condition considered the difference of maneuverability due to gains. The third condition considered the difference of maneuverability between two handle operations in real running space in a condition of 10 gains. In a result of the first condition, a subject who was used to ride run effectively and running time is short compared with a subject who was used to ride. However, in handle yaw rotation, the difference of maneuverability was small. In a result of the second condition, running mileage about the same in two handle operation, but running time of handle yaw rotation is shorter than that of handle roll rotation. In a result of the third condition, like the second condition, running time of handle yaw rotation is shorter than that of handle roll rotation. In questionnaire evaluation, the best gain is the lower gain, 0.02 . At last, An experiment was carried out by 14 subjects in the best gain, 0.02 that is best both handle operation. In the result of this experiment, 12 subjects answered that handle yaw rotation is better than handle roll rotation.
\end{abstract}

Keywords-personal mobility vehicle; inverted pendulum vehicle; maneuverability; handle operation; number of operations; questionnaire evaluation

\section{INTRODUCTION}

Environmental and energy problems are of increasing interest, and alternative means of transportation have been considered to solve this problem. Daily transportation involves walking, bicycles, and cars depending on the time and situation. Recently, personal mobility vehicles (PMVs) — which are environmentally friendly and useful for short- to mid-range transportation-have attracted some attention.

Some examples of PMVs include inverted pendulum vehicles such as the Segway and the Winglet. In addition to their usefulness over short- to mid-range distances, inverted pendulum vehicles are either human-powered or electrically powered, which emit no exhaust gas and are thus environmentally friendly. For this reason, the use of such vehicles has been spreading for security and recreational activities. For ensuring their convenient use, verification experiments have been made for the implementation of PMVs as efficient and user-friendly transportation systems.

The studies of PMVs include those focused on the improvements and usage of common PMVs, as well as those on developing new PMVs such as high-performance wheel chairs and amphibious bicycles and tricycles. Studies on inverted pendulum vehicles include those focusing on the stability and relationships between the vehicle and the controller and between the vehicle and pedestrians. Controllability studies on PMVs involve the investigation of the stable driving of rides using bicycle steering, model analysis, and braking. However, few studies have focused on the vehicle's handle operation and controllability.

This study focused on two types of operations:

1) Turns by holding down the handle axis (handle roll rotation) and

2) Turns by rotating the handle (handle yaw rotation).

The purpose of this study is to experimentally compare the controllability of the two types of handle operation.

\section{TEST VEHICLE}

The handle of the test vehicle used in this study was replaceable. The handle of the test vehicle could be either of the handle roll rotation (Fig. 1) or the handle yaw rotation (Fig. 2) variety. The maximum rotation of the handle roll rotation was $20^{\circ}$ to the left and the right, and that of the handle yaw rotation was $30^{\circ}$ to the left and the right. The vehicle equipped with a Bluetooth communication function for measuring the number of wheel rotations and handling angle. The data sampling period for the measurements was $0.1 \mathrm{~s}$.

\section{CONTROLLABILITY EXPERIMENT}

The experiments were carried out under the three conditions listed below.

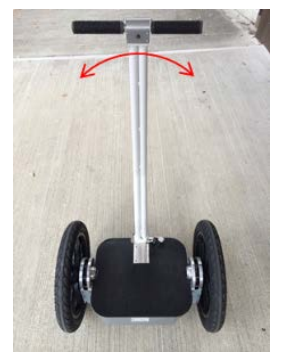

Fig. 1. Handle roll rotation 


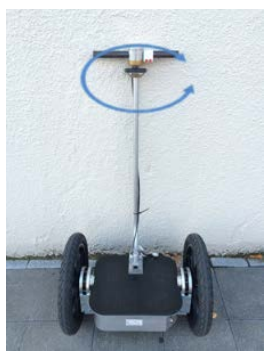

Fig. 2. Handle yaw rotation

Condition 1: Using both experienced and inexperienced drivers for the comparison

Condition 2: Selection of steering gain

Condition 3: Comparison of the controllability of the handle roll rotation and the handle yaw rotation

The condition 1 studied the behaviors of experienced drivers (who had driven10 times or more) and completely inexperienced drivers. The condition 2 selected the most appropriate steering gain for each handle operation. The condition 3 investigated which handle operation had better controllability.

\section{A. Difference Between The Experienced And Inexperienced Drivers}

This experiment was carried out under the conditions shown in Table 1 . The drivers were six adult males, five of whom were experienced and one of whom was inexperienced. The test course was a slalom with two cones with a distance of $1.8 \mathrm{~m}$ between them, as shown in Fig. 3. The driving trajectory was measured using a three-dimensional operation analysis device (VICON). Each driver rode around the slalom for three cycles with each of the two handle operations and three different gains, i.e., large (0.02), medium (0.012), and small (0.008), making a total of six patterns. After the test rides, the drivers answered a five-level controllability evaluation survey.

TABLE I. EXPERIMENTAL CONDITION 1

\begin{tabular}{|l|l|}
\hline Subjects & 6 (5 experienced, 1 inexperienced) \\
\hline Course & Two cones with a distance of $1.8 \mathrm{~m}$ \\
\hline Gain & $0.02,0.012$, and 0.008 \\
\hline Cycles & 3 \\
\hline Order & $0.02,0.012$, and 0.008 , each with 3 cycles \\
\hline
\end{tabular}

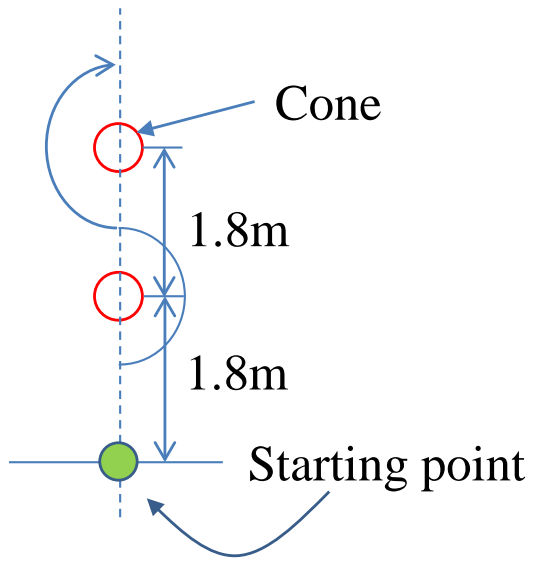

Fig. 3. Experimental Course

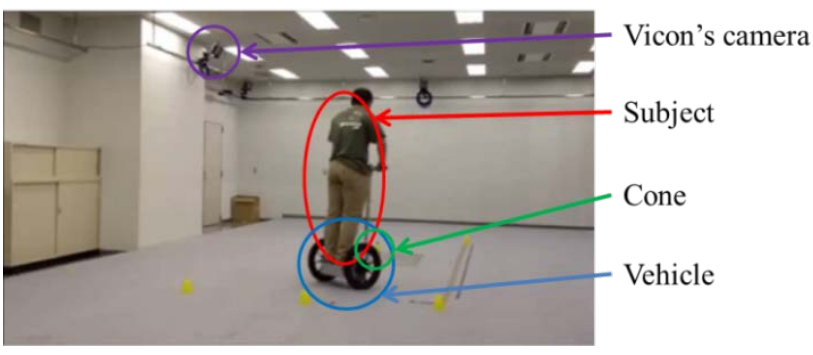

Fig. 4. Experimental Course

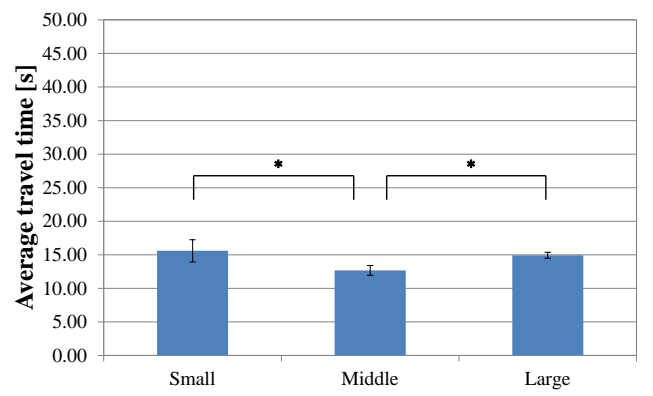

Fig. 5. Average travel time (roll, experienced driver)

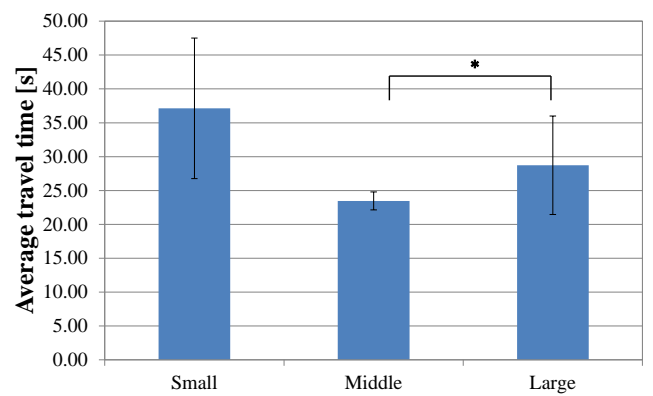

Fig. 6. Average travel time (roll, inexperienced driver)

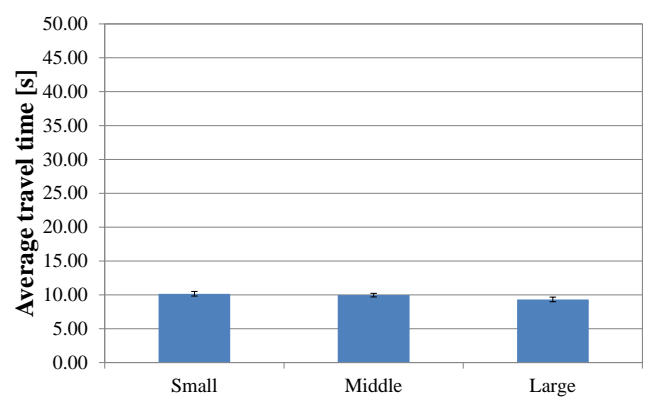

Fig. 7. Average travel time (yaw, experienced driver)

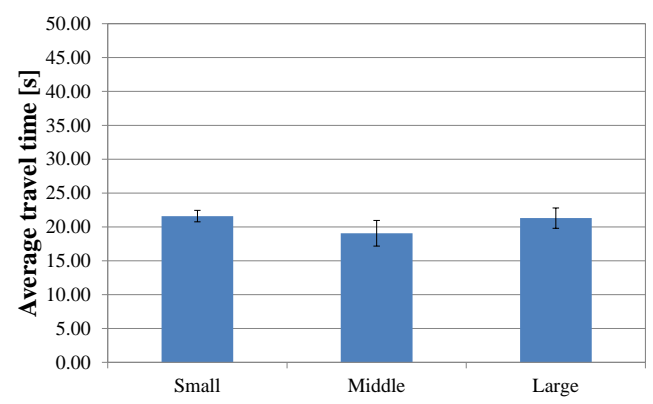

Fig. 8. Average travel time (yaw, inexperienced driver) 
Fig. 5 and Fig. 6 show the ride times of the experienced and inexperienced drivers, respectively, with handle roll rotation. Fig. 7 and Fig. 8 show these ride times with handle yaw rotation. Comparing the rides of the experienced and inexperienced drivers revealed that the both types of the driver had smaller handle angles with increasing steering gain. The inexperienced driver's ride time was significantly longer than those of the experienced drivers in both handle roll rotation and handle yaw rotation. The difference in the ride time between the experienced and inexperienced drivers was smaller for the handle yaw rotation than that for the handle roll rotation.

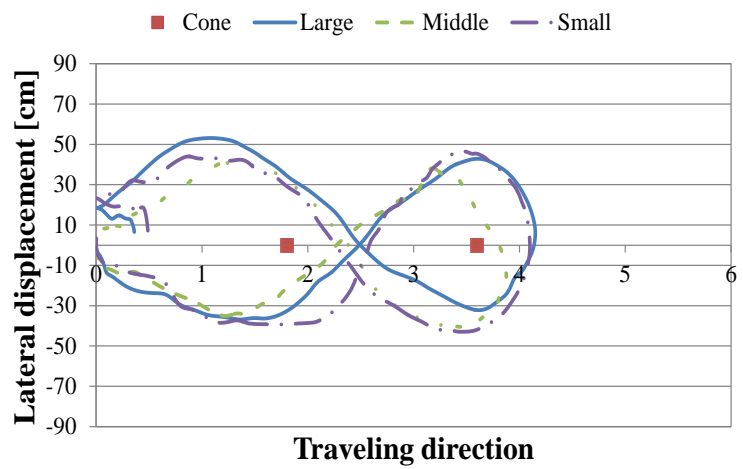

Fig. 9. Trajectory of the experienced driver (handle roll rotation)

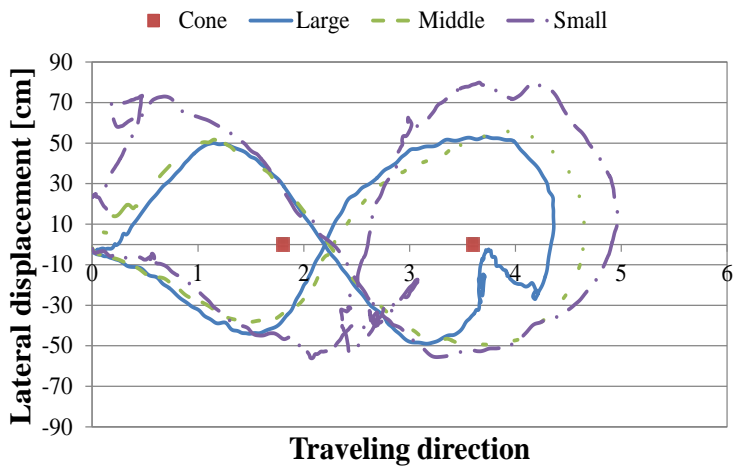

Fig. 10. Trajectory of the inexperienced driver (handle roll rotation)

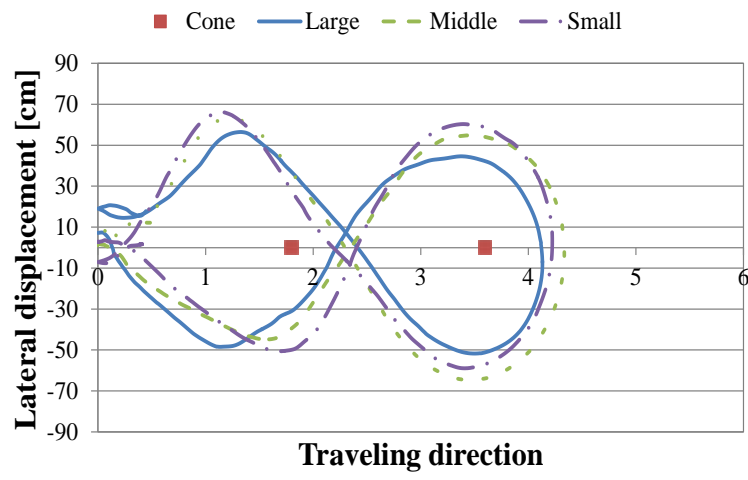

Fig. 11. Trajectory of the experienced driver (handle yaw rotation)

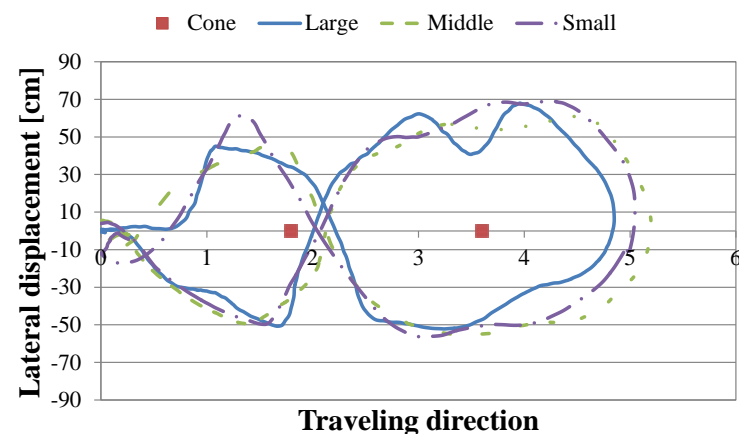

Fig. 12. Trajectory of the inexperienced driver (handle yaw rotation)

Fig. 9 and Fig. 10 are the drive trajectories of the experienced and inexperienced drivers, respectively, using handle roll rotation; similarly, Figs. 11 and Fig. 12 are those with handle yaw rotation. With both handle operations, the inexperienced driver had trajectories that were compared with those of the experienced drivers. Moreover, Fig. 13 and Fig. 14 show that the inexperienced driver cut the wheel more than the experienced drivers. Here, "cutting the wheel" means the change of sign of the handle angular velocity.

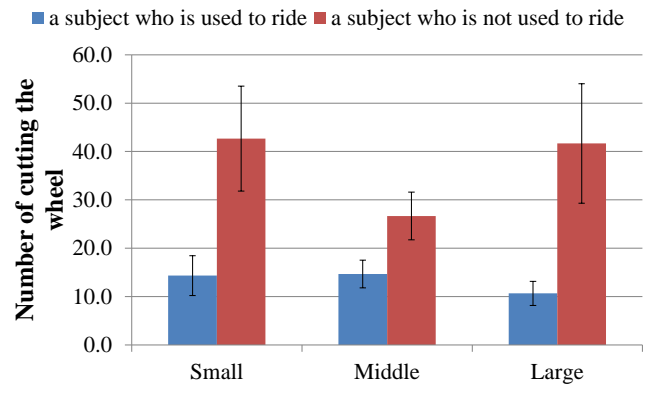

Fig. 13. Amount of cutting of the wheel (handle roll rotation)

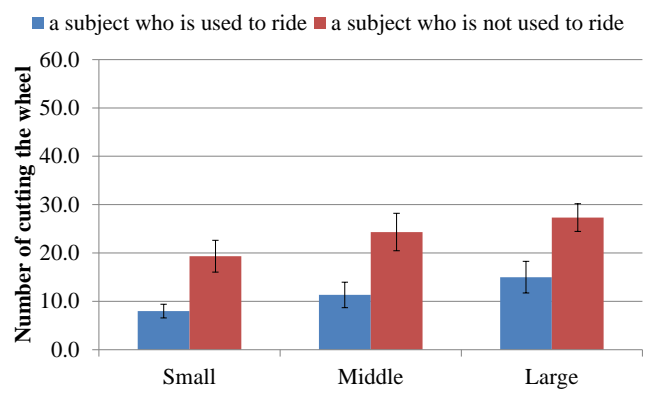

Fig. 14. Amount of cutting of the wheel (handle yaw rotation)

\section{B. Selection of Steering Gain}

This experiment was conducted under the conditions shown in Table 2. Five male adult subjects drove on a slalom course with combinations of large $(1.8 \mathrm{~m})$ and small $(1.4 \mathrm{~m})$ distances between the cones. Each subject made two cycles around the course for each of the five steering gains; 0.012, 0.02, 0.03, 0.04 , and 0.05 . This study included gains larger than 0.05 ; 
0.06, 0.07, 0.08, 0.09, and 0.1 in the survey. Considering the order effect, the steering gains were measured in the order $0.012,0.03,0.02,0.04$, and 0.05 . For the survey, the gains were placed in the order $0.06,0.08,0.07,0.1$, and 0.09 in addition to the former gain order. The subjects answered an evaluation survey after the test drives.

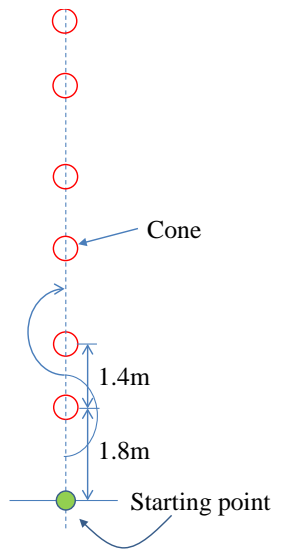

Fig. 15. Experimental course

TABLE II. EXPERIMENTAL CONDITION 2

\begin{tabular}{|l|l|}
\hline Subjects & 5 (All experienced) \\
\hline Course & At an interval combination of $1.8 \mathrm{~m}$ and $1.4 \mathrm{~m}$ \\
\hline \multirow{3}{*}{ Gain } & Five gains for data collection: $0.012,0.02,0.03,0.04$ and 0.05. \\
\cline { 2 - 2 } & $\begin{array}{l}\text { Ten gains for survey: } 0.06,0.07,0.08,0.09, \text { and } 0.1 \text { in addition to } \\
\text { the above five gains }\end{array}$ \\
\hline Cycles & 2 \\
\hline \multirow{2}{*}{ Orders } & Data collection: $0.012,0.03,0.02,0.04$, and 0.05 , each two cycles \\
\cline { 2 - 2 } & For survey: $0.06,0.08,0.07,0.1$, and 0.09 , each 2 cycles \\
\hline
\end{tabular}

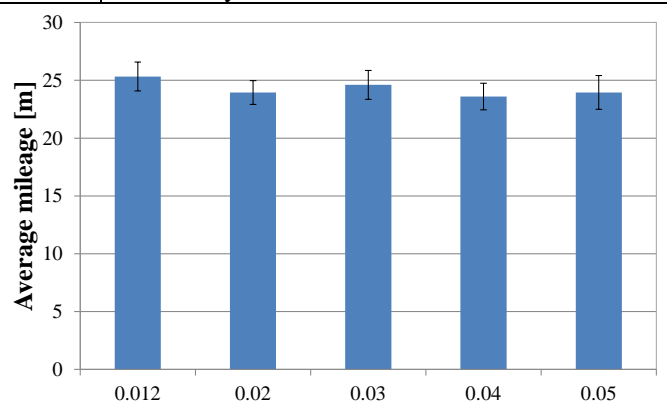

Fig. 16. Average mileage (handle roll rotation)

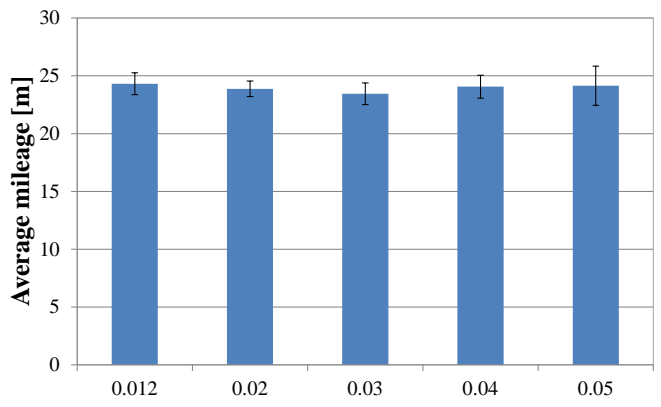

Fig. 17. Average mileage (handle yaw rotation)

Fig. 16 and Fig. 17 show the distances traveled; Fig. 18 and Fig. 19 show the ride times; Fig. 20 and Fig. 21 show the numbers of cuttings of the handle, in other words, changes in the turning direction of the handle. Similar to the section 3.1, the handling angles become smaller as the steering gain increase for both handle operations. There was almost no difference in the distance traveled between the two handle operations. On the other hand, the ride time with handle yaw rotation was approximately $6 \mathrm{~s}$ shorter than that with handle roll rotation. Moreover, the amount of cutting of the handle was less for the handle yaw rotation for all the steering gains. These comparison implied a higher efficiency of the handle yaw rotation.

The survey results were evaluated from two aspects: the handling performance, which pertained to the controllability, and riding performance, which was related to the balance of the ride. Fig. 22 and Fig. 23 show the results of the handling performance of the handle roll rotation and handle yaw rotation, respectively. Fig. 24 and Fig. 25 are the results of the controlling performance. The vertical axis shows the rating with 5 being the most and 1 the least desirable riding conditions. The error bars show the standard deviations. In both surveys, the steering gain of 0.02 had the highest ratings.

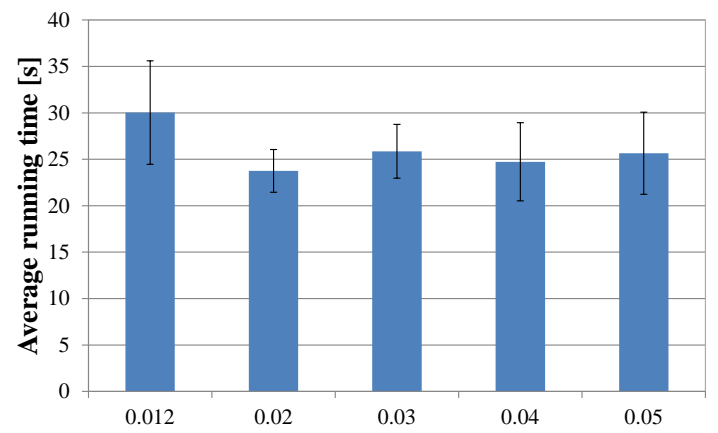

Fig. 18. Average running time (handle roll rotation)

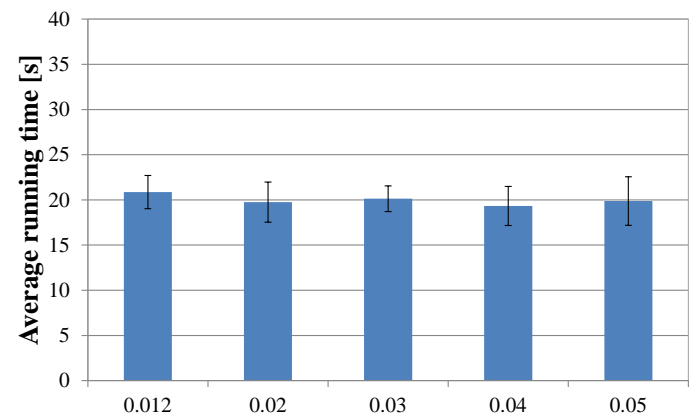

Fig. 19. Average running time (handle yaw rotation)

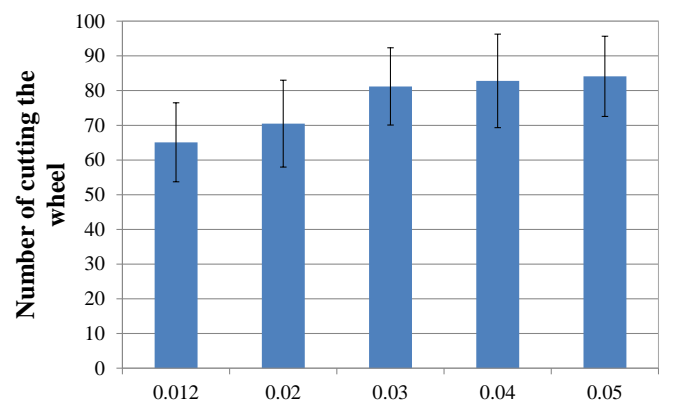

Fig. 20. Amount of cutting of the wheel (handle roll rotation) 


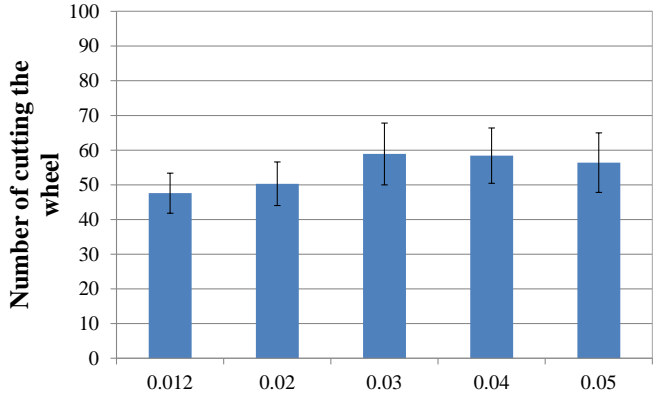

Fig. 21. Amount of cutting of the wheel (handle yaw rotation)

\section{Comparison Of The Controllability Of Handle Roll Rotation And Handle Yaw Rotation}

In this section, it is examined which handle operationhandle roll or handle yaw-was better based on the experiment and survey results. By using the gain of the highest rating ( 0.02 for both handle roll rotation and handle yaw rotation) as shown in section $B$, answers to a survey were obtained from 14 subjects. The test course was a slalom with three cones with an equal distance of $1.8 \mathrm{~m}$. The subjects were adult males and females, and none were experienced in driving these vehicles. The method of answering the survey was the same five-level rating as in the previous section. Fig. 26 and Fig. 27 show the five-level survey results for the respective handle operations. Of the 14 subjects, two answered that the handle roll rotation had better controllability than did the handle yaw rotation, and 12 answered the other way around. As a result of a sign test, there was a significant difference between the two handle operations, as shown in Fig. 28, which indicates that the handle yaw rotation has better controllability. Moreover, there was no subject who indicated that the handle yaw rotation was difficult to ride. The above results thus suggest that handle yaw rotation has better controllability.

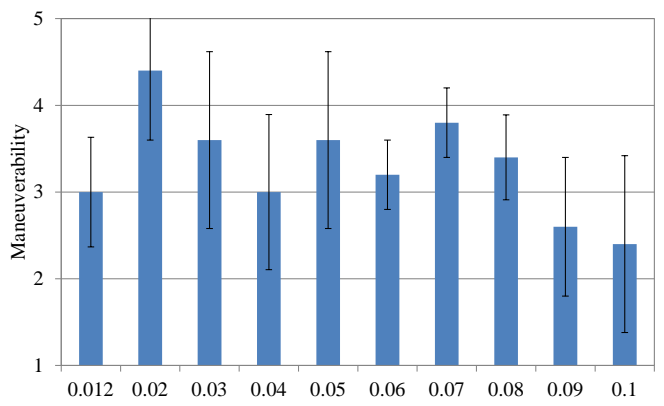

Fig. 22. Questionnaire result of handle roll rotation (handle operation)

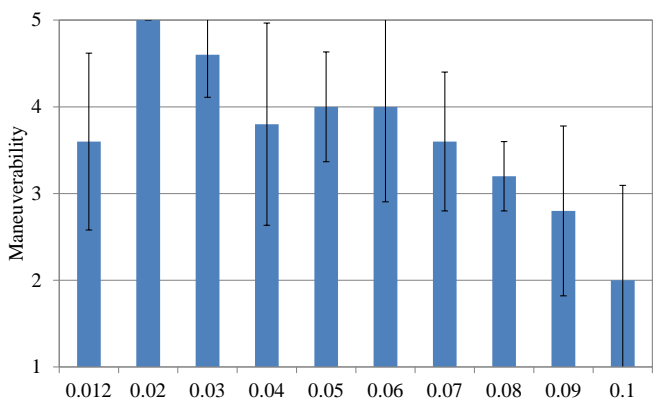

Fig. 23. Questionnaire result of handle yaw rotation (handle operation)

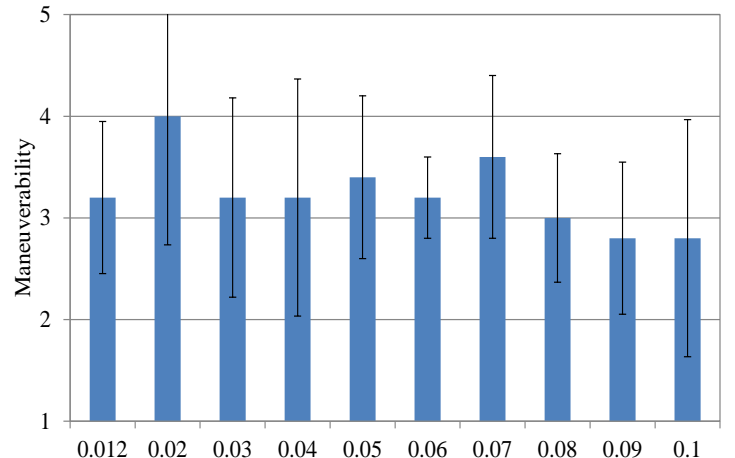

Fig. 24. Questionnaire result of handle roll rotation (running operaion)

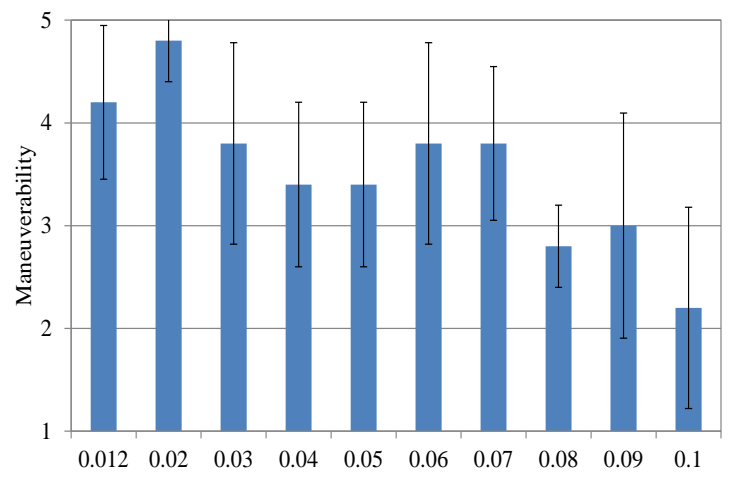

Fig. 25. Questionnaire result of handle yaw rotation (running operation)

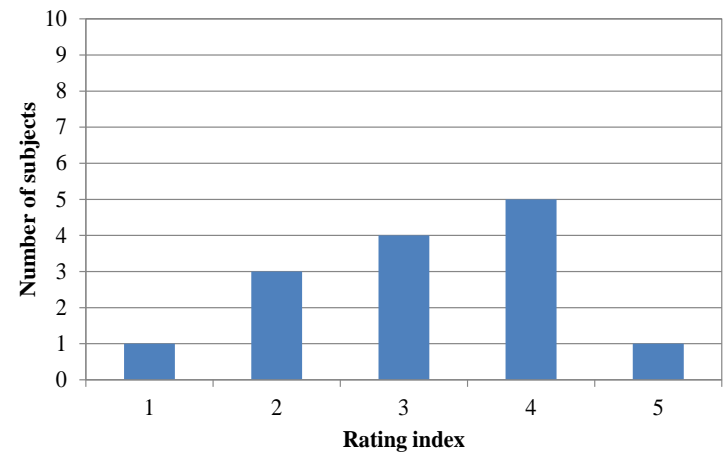

Fig. 26. Questionnaire result of handle yaw rotation

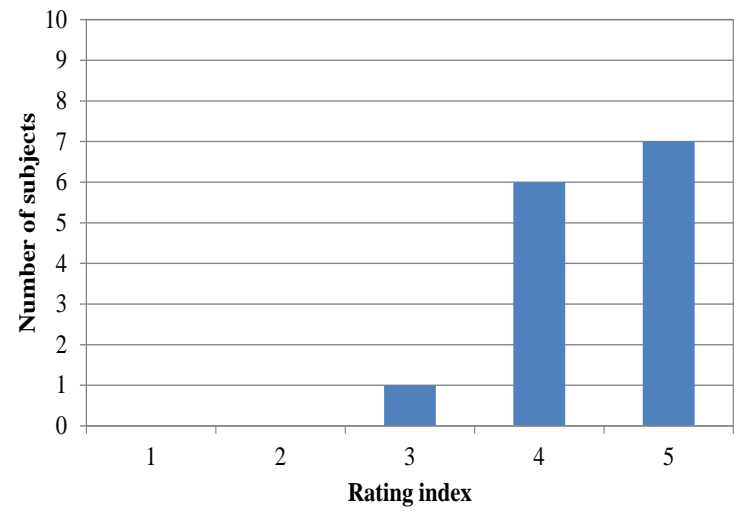

Fig. 27. Questionnaire result of handle yaw rotation 


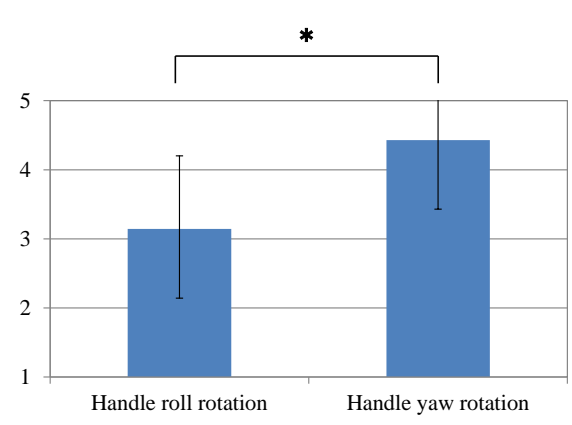

Fig. 28. Comparison of evaluation

\section{DISCUSSIONS}

This section discusses the characteristic differences between the handle roll rotation and the handle yaw rotation and these effect. In handle roll rotation, the driver's body tends to tilt as the handle is held down from left to right and vice versa. Consequently, the ride easily goes off course on a slalom as the driver's body tilts frequently. In handle yaw rotation, on the other hand, the handle axis is fixed, and the steering is performed by rotating the handle in the direction of the yaw. Unlike handle roll rotation, this method allows steering in the upright position, leading to stability without tilting the driver's body to the right or the left, even during sharp turns. The unfavorable results for handle roll rotation obtained in section $C$ were because inexperienced drivers were likely to feel instability while controlling the vehicle with their bodies tilted.

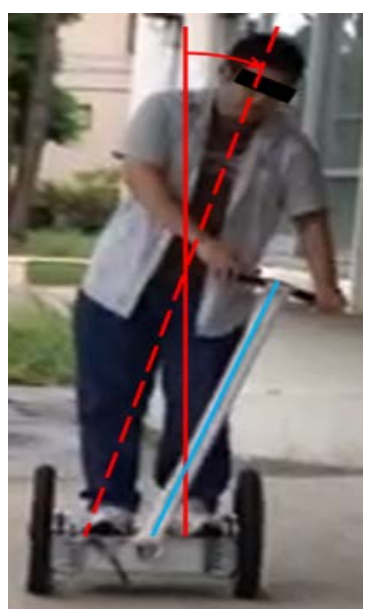

Fig. 29. State of handle roll rotation

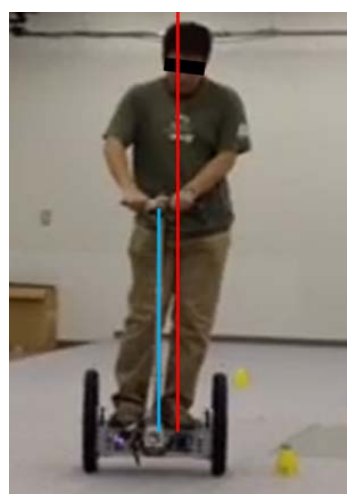

Fig. 30. State of handle yaw rotation

\section{CONCLUSION}

As a result of this study, it is discovered that both experienced and inexperienced drivers found the handle yaw rotation easier to control. This is likely because handle roll rotation involves tilting one's body while handle yaw rotation does not. As the driver experiences centrifugal force while steering, the force is larger for handle roll rotation than for handle yaw rotation. Thus, it is likely that the inexperienced drivers felt instability upon steering, leading to a higher rating for handle yaw rotation than that for handle roll rotation.

\section{REFERENCES}

[1] Segway http://www.segway-japan.net/index.html (accessed on January 26, 2015)

[2] Winglet

http://www.toyota.co.jp/jpn/tech/personal_mobility/winglet.html (accessed on January 26, 2015)

[3] Segway Implementation results available from http://www.segwayjapan.net/casestudy/police/ (accessed on January 26, 2015)

[4] Robot special district validation and experiment promotion council available from http://council.rt-tsukuba.jp/ (accessed on January 26, 2015)

[5] Start of road test of Winglet, Toyota's standing ride robot, available from http://ascii.jp/elem/000/000/811/811044/ (accessed on January 26, 2015)

[6] Miura, M. and Takahashi, Y., Proposal for Personal Mobility Vehicle for People with Limited Mobility, the Japan Society of Mechanical Engineers, the Transportation and Logistics Conference 2010(19), 2010, pp. 299-302.

[7] Mizokami, S., Kawashima, H and Yaguchi, T., A Study of Potential for QOL Improvements through the Use of Personal Mobility in an 'Aged Society', Internal Association of Traffic and Safety Science, IATSS review 36(3), 2012, pp. 44-51.

[8] Ono, H., Yoshiko, K., Ohsaki, H., Hirahara, H., Watanabe, K., Iwase, M. and Hatakeyama, S., Design of structure and control for bicycle operation assist system, Proceedings of the Japan Joint Automatic Control Conference 50(0), 2007, pp. 194-194.

[9] Satoh, Y. and Sakaue, K., A secure and reliable next generation mobility: an intelligent electric wheelchair with a stereo omnidirectional camera system, National Institute of Advanced Industrial Science and Technology, Synthesiology 2(2), 2009, pp. 113-126.

[10] Toda, M., Design and production of amphibious bicycle of a removable system, Polytechnic College Kinki Proceedings, (18), 2014, pp. 6-10.

[11] Akita, H., The Structure and its Development of an Electric Power Assisted Cycle, Japanese Society of Automotive Engineers, JSAE, 63(9), 2009, pp. 50-54.

[12] Ishikawa, T., Takafumi, F., Terauchi, F., Kubo, M. and Aoki, H., A Front-Wheel-Drive Tricycle by using the Elastic Behavior of the Rear Frames, Proceedings of the Annual Conference of JSSD (51), 2004, pp. 70-71.

[13] Nakano, K., Nakamori, D., Zheng, R., Ohori, M. and Suda, Y., Stability Analysis on a Two-Wheeled Inverted Pendulum Type Personal Mobility Vehicle Considering Human Motion, The Japan Society of Mechanical Engineers, TRANSACTIONS OF THE Japan SOCIETY OF MECHANICAL ENGINEERS Series C 79(801), 2013, pp. 1427-1440.

[14] Nakamori, D., Nakano, K., Ohori, M. and Suda, Y., Relations Between Stability and Ride Comfort of the Two-wheeled Inverted Pendulum Vehicle, The Japan Society of Mechanical Engineers, The Transportation and Logistics Conference 2011, pp. 163-166.

[15] Suda, Y., Hirayama, Y., Yamaguchi, D. and Aki, M., Communication with Personal Mobility Vehicle and Driver, SEISAN KENKYU 64(2), 2012, pp. 71-74.

[16] Arakawa, S., Nakagawa, C., Shintani, A. and Ito, T., Basic Study on the Behavior of Inverted Pendulum Vehicle and Driver Using Multibody Dynamics, The Japan Society of Mechanical Engineers, TRANSACTIONS OF THE JAPAN SOCIETY OF MECHANICAL ENGINEERS Series C 78(789), 2012, pp. 1497-1506. 
[17] Nakagwa, C., Imamura, K., Shintani, A. and Ito, T., Experimental Study on the Influence of the Size of Personal Mobility Vehicle on Pedestrians, the Japan Society of Mechanical Engineers, TRANSACTIONS OF THE JAPAN SOCIETY OF MECHANICAL ENGINEERS Series C 78(794), 2012, pp. 3332-3342.

[18] Maeda, K. and Yamada, M., Stable running by the steering of two-wheel self-propelled bicycle, The Japan Joint Automatic Control Conference, Proceedings of the Japan Joint Automatic Control Conference 49(0), 2006, pp. 175-175.

[19] Katayama, T., Kinetic model for stability and safety analyses of bicycles, Japan Bicycle Promotion Institute, Bicycle Technology Information (77), 2000-02, pp. 1-16.

[20] Matsui, H., et al., Bicycle braking by college students, adults and seniors, Japan Bicycle Promotion Institute, Bicycle Technology Information (20), 1983-2007, pp. 25-30.

[21] Oguro, H. and Raksincharoensak, P., Study on Driving Characteristics of Two-Wheel Inverted Pendulum Electric Vehicle in Pedestrian Walking Space, The Japan Society of Mechanical Engineers, Robotics/mechatronics conference proceedings, 2011, "2A1-Q13 (1)""2A1-Q13 (2)."

[22] Suda, Y., Hirayama, Y. and Takagi, M. A. T., Yaw Control Experiment of Tricycle-type Personal Mobility Vehicle: Maneuvering Experiment by Different Rotation Speed Control in Right and Left Wheel. The Japan Society of Mechanical Engineers, Dynamics \& Design Conference 2011, 2011, “148-1”-“148-8.”

[23] Nakagawa, C., Suda, Y., Nakano, K. and Hirayama, Y., Maneuvering Experiment of Parallel Two-Wheeled Personal Mobility Vehicle with Human Pedaling, Institute of Industrial Science The University of Tokyo, SEISAN KENKYU 62(1), 2010, pp. 119-122.

[24] Horiuchi, E., Matsumoto, O., Takei, T., Koyachi, N., Hashimoto, T., Ando, T. and Iwao, K., A Steering Assist Method for Formation Control of Personal Vehicles, The Robotics Society of Japan, JRSJ 28(10), 2010, pp. 1243-1250.
[25] Nakagawa, C., Imamura, K., Shintani, A. and Ito, T., Experimental Study on the Influence of the Size of Personal Mobility Vehicle on Pedestrians , the Japan Society of Mechanical Engineers, TRANSACTIONS OF THE JAPAN SOCIETY OF MECHANICAL ENGINEERS Series C 78(794), 2012, pp. 3332-3342.

[26] Maeda, K. and Yamada, M., Stable running by the steering of two-wheel self-propelled bicycle, The Japan Joint Automatic Control Conference, Proceedings of the Japan Joint Automatic Control Conference 49(0), 2006, pp. 175-175.

[27] Katayama, T., Kinetic model for stability and safety analyses of bicycles, Japan Bicycle Promotion Institute, Bicycle Technology Information (77), 2000-02, pp. 1-16.

[28] Matsui, H., et al., Bicycle braking by college students, adults and seniors, Japan Bicycle Promotion Institute, Bicycle Technology Information (20), 1983-07, pp. 25-30.

[29] Oguro, H. and Raksincharoensak, P., Study on Driving Characteristics of Two-Wheel Inverted Pendulum Electric Vehicle in Pedestrian Walking Space, The Japan Society of Mechanical Engineers, Robotics/mechatronics conference proceedings, 2011, "2A1-Q13 (1)""2A1-Q13 (2)."

[30] Suda, Y., Hirayama, Y. and Takagi, M. A. T., Yaw Control Experiment of Tricycle-type Personal Mobility Vehicle: Maneuvering Experiment by Different Rotation Speed Control in Right and Left Wheel. The Japan Society of Mechanical Engineers, Dynamics \& Design Conference 2011, 2011, “148-1”-“148-8."

[31] Nakagawa, C., Suda, Y., Nakano, K. and Hirayama, Y., Maneuvering Experiment of Parallel Two-Wheeled Personal Mobility Vehicle with Human Pedaling, Institute of Industrial Science The University of Tokyo, SEISAN KENKYU 62(1), 2010, pp. 119-122.

[32] Horiuchi, E., Matsumoto, O., Takei, T., Koyachi, N., Hashimoto, T., Ando, T. and Iwao, K., A Steering Assist Method for Formation Control of Personal Vehicles, The Robotics Society of Japan. 